удк 332.1

Ю. А. Бергер

Волгоградский институт бизнеса, г. Волгоград, Российская Федерация

\author{
ПРОБЛЕМЫ И ПЕРСПЕКТИВЫ \\ СОЦИАЛЬНО-ЭКОНОМИЧЕСКОГО РАЗВИТИЯ \\ МУНИЦИПАЛЬНЫХ РАЙОНОВ ВОЛГОГРАДСКОЙ ОБЛАСТИ \\ (ОБЗОР НАУЧНЫХ ПУБЛИКАЦИЙ)
}

\begin{abstract}
АНнотАция. В статье приводится обзор научных публикаций, которые раскрывают проблему социально-экономического развития муниципальных районов Волгоградской области. Делается акцент на том, что развитие страны в целом напрямую зависит от устойчивого развития региональных и муниципальных систем. Рассматриваются три направления исследований, по каждому из которых систематизирована информация по проблемам социально-экономического развития муниципальных районов Волгоградской области, тенденциям развития сельского хозяйства, вопросам муниципального управления и оценки его эффективности. Социально-экономическое развитие муниципальных районов исследовано с помощью выделения ряда показателей, характеризующих уровень их развития, группировки территории по определенным признакам, применения различных технологий для управления системами. Пытаясь оценить уровень социально-экономического развития муниципальных территорий, осуществлен анализ данных из официальных статистических сборников и паспортов муниципальных образований. Представлен результат разработки и реализации методов, механизмов, интегральных показателей, способных переломить критическую ситуацию в сельских территориях. В конечном итоге предлагается решение проблемы социально-экономического развития муниципальных районов: создание агрохолдингов; объединение учебно-научных центров и производственных баз; оптимизация системы расселения; усиление взаимосвязи между социально-экономическим развитием муниципальной территории и оценкой эффективной деятельности органов местного самоуправления.

кЛючЕВЫЕ СЛОВА. Российская Федерация; регион; региональная экономика; социально-экономическое развитие; муниципальное управление; муниципальные районы; органы местного самоуправления; система расселения; муниципальные территории; агрохолдинг.

ИНФОРМАЦИЯ О СТАТЬЕ. Дата поступления 27 ноября 2015 г.; дата принятия к печати 25 декабря 2015 г.; дата онлайн-размещения 29 января 2016 г.
\end{abstract}

\title{
PROBLEMS AND PROSPECTS OF SOCIO-ECONOMIC DEVELOPMENT OF THE MUNICIPAL DISTRICTS OF VOLGOGRAD OBLAST (REVIEW OF SCIENTIFIC PUBLICATIONS)
}

ABSTRACT. The article provides an overview of scientific publications that reveal the
problems of social and economic development of municipal districts of Volgograd Oblast.
It accentuates the fact that the country's development on the whole is directly depen-
dent on sustainable development of regional and municipal systems. It considers three
directions of research studies while which of them incorporates systemized information
on problems of socio-economic development of Volgograd Oblast's municipal districts,
on tendencies of agricultural development, on issues of municipal administration and
assessment of its efficiency. The socio-economic development of municipal districts is

(C) Ю. А. Бергер

\section{Baikal Research Journal}

электронный научный журнал Байкальского государственного университета 
investigated with help of identifying a number of indictors that characterize the level of their development, grouping territories in terms of certain features, using various technologies of system management. While trying to assess the level of socio-economic development. The article makes an analysis of the data from official statistical books and passports of municipal entities. It presents the results of development and implementation of the methods, mechanisms, integral indictors that are able to make a critical difference in agricultural territories. Finally, it offers a solution of the problem of socio-economic development of the municipal districts: creation of agriholdings; integration of teaching and research centers and production facilities; optimization of the settlement system; strengthening the assessment of local government bodies' efficient activities.

KEYWORDS. The Russian Federation; region; regional economy; socio- economic development; municipal administration; municipal districts; local government bodies; system of settlement; municipal territories; agricultural holding.

ARTICLE INFO. Received November 27, 2015; accepted December 25, 2015; available online January 29, 2015.

Глобализация мировой экономики оказывает существенное влияние на развитие внутригосударственных экономических систем. Стремление Российской Федерации стать полноправным участником мировых хозяйственных процессов предполагает формирование новой системы институтов международного взаимодействия и создание более совершенных инструментов управления этими процессами.

Особенности территориального устройства государства, базирующиеся на принципе федерализма, определяют значение каждого конкретного региона для развития экономики России в целом. Совершенно очевидно, что без разработки продуманной траектории развития регионов интеграция российской экономики в мировую будет затруднена.

Исследования современных ученых подтверждают тот факт, что устойчивое развитие региональных экономических систем напрямую зависит от уровня развития муниципальных территорий. Пристальное внимание поэтому следует уделять муниципальным районам, так как именно они являются непосредственными участниками решения вопросов развития территорий.

Сложившаяся за последние десятилетия тенденция снижения численности сельского населения за счет миграционного оттока в большие города постепенно стала причиной опустения сельских территорий муниципальных районов. Результат - критическое положение в сельском хозяйстве с трудовыми ресурсами. Это стало основной причиной разработки мероприятий, способствующих устойчивому развитию села, так как «без сохранения и развития села невозможно гармоничное развитие нашей страны, рост ее конкурентоспособности» [1].

В стране предпринимаются попытки решить эту проблему при помощи внедрения Концепции устойчивого развития сельских территорий Российской Федерации на период до 2020 года ${ }^{1}$ и Федеральной целевой программы «Устойчивое развитие сельских территорий на 2014-2017 гг. и на период до 2020 года» ${ }^{2}$. Цель ее - выявление основных проблем развития сельских территорий, а также разработка мер правового, социально-экономического и административного характера. Однако для реализации Концепции необходимы не только новые стратегические планы развития территорий, но и новые научно-методологические подходы, интегральные показатели, комплексно характеризующие уровень развития муниципальных рай-

${ }^{1}$ Об утверждении Концепции устойчивого развития сельских территорий Российской Федерации на период до 2020 года : распоряжение Правительства РФ от 30 нояб. 2010 г. № 2136-р // Собрание законодательства Российской Федерации. 2010. № 50. Ст. 6748.

${ }^{2}$ О Федеральной целевой программе «Устойчивое развитие сельских территорий на 2014-2017 годы и на период до 2020 года» : постановление Правительства РФ 15 июля 2013 г. № 598 // Собрание законодательства Российской Федерации. 2013. № 30, ч. II. Ст. 4110.

\section{Baikal Research Journal}


онов, создание системы оперативного мониторинга, привлечение системы информационных технологий в прогнозировании и планировании.

Одним из способов решения существующей проблемы может послужить анализ научных взглядов ученых и опыта внедрения различных технологий на территориях регионов. В связи с этим предлагается систематизация различных взглядов ученых Волгоградского региона на решение рассматриваемой проблемы.

Цель данного исследования - выявить наиболее актуальные предложения ученых региона и реальные возможности перспективного развития муниципальных районов Волгоградской области.

Для анализа и систематизации информации было выделено несколько направлений исследований:

- проблемы социально-экономического развития муниципальных районов Волгоградской области;

- тенденции развития сельского хозяйства районов области;

- вопросы муниципального управления и оценка его эффективности.

В нашем случае социально-экономическое развитие муниципальных районов исследовали с помощью выделения ряда показателей, характеризующих уровень их развития, группировки территории по определенным признакам, применения различных технологий для управления системами. Пытаясь оценить уровень социально-экономического развития муниципальных территорий, был осуществлен анализ данных, представленных в официальных статистических сборниках за ряд лет и паспортов муниципальных образований.

Отдельные авторы рассматривают проблему перспективного развития муниципальных территорий Волгоградской области через призму системных подходов, метода кластеризации, геоинформационных технологий, КУБ-индикаторов.

Группа авторов Волгоградского государственного аграрного университета под руководством кандидата экономических наук, доцента С. А. Поповой выявили проблемы развития сельских территорий, разделив их на четыре блока: социальные, экономические, политические, а также проблемы сохранения природного и культурного потенциала [2-5]. Они в очередной раз подтверждают неутешительную статистику демографической ситуации в муниципальных районах, несоответствие в оплате труда, низкий уровень занятости сельского населения. Исследователи придерживаются мнения о том, что основная причина оттока населения из муниципальных образований, и как следствие - сокращение его численности, связана с отсутствием перспектив в решении жилищной проблемы, а также неразвитой социальной и инженерной инфраструктуры. Решив эти проблемы, по их мнению, можно выйти на траекторию устойчивого развития сельских территорий.

С мнением этой группы соглашаются многие ученые, но лишь с одной поправкой о том, что решение жилищных проблем и развитие социальной инфраструктуры не являются главными факторами улучшения положения в сельских поселениях. Все же первостепенно - отсутствие мест приложения труда. При создании на территориях муниципальных образований рабочих мест развивается и весь спектр социальной и инженерной инфраструктуры, с этим фактом согласны практически все исследователи, занимающиеся вопросами региональной экономики.

Представляется актуальными работы доктора экономических наук А. В. Плякина, в которых предлагается совершенствовать технологии измерения уровня развития муниципальных районов, использовать геоинформационные технологии для управления региональными системами. Автор в своих исследованиях произвел попытку создания системы комплексной оценки развития муниципалитетов, разработав группу КУБ-индикаторов, отражающих «обеспечение конкурентоспособности муниципальных хозяйств, устойчивости и безопасности их развития» [6-9].

\section{Baikal Research Journal}


В некоторых работах обращается внимание на существенную проблему транспортной инфраструктуры региона и ее влияние на уровень социально-экономического развития муниципальных территорий. Доказывается, что у поселений и районных центров с более выгодным местоположением гораздо больше возможностей успешного развития, поскольку транспортная инфраструктура напрямую выражает «степень закрепленности населения на территории области» [10].

Коллектив авторов Волгоградского государственного технического университета предлагает для выявления проблем социально-экономического развития муниципальных образований использовать инструменты анализа данных «DATA MINING». Исходными данными исследования выступают паспорта муниципальных образований. На их основе с помощью метода кластеризации были построены так называемые «карты параметров, дающие возможность оценки ситуации и сравнения с другими сельскими поселениями» [11]. Выявлены наиболее благоприятные поселения относительно развития малых форм хозяйствования.

Изучая развитие муниципальных районов области, Е. В. Михайлова и О. Г. Зубова выделяют как первоочередную проблему оптимизации системы сельского расселения и предлагают решить ее за счет укрупнения путем объединения экономически неэффективных поселений с более сильными. Поскольку, по мнению авторов, крупные сельские поселения «располагают значительными производственными мощностями и концентрацией рабочей силы, они должны стать хозяйственными центрами, на территории которых размещаются крупные производства» [12]. Результатом таких преобразований станет повышение эффективности территориального управления, новая экономически обоснованная пространственная организация территории.

Различные подходы авторов к решению проблем социально-экономического развития муниципальных территорий создают базу для формирования единой комплексной системы, элементы которой должны находиться в постоянной взаимосвязи.

Второе направление представлено работами ученых, занимающихся проблемами развития сельского хозяйства муниципальных районов Волгоградской области.

Без анализа использования земель сельскохозяйственного назначения рассмотрение тенденций развития сельского хозяйства Волгоградской области было бы неполным. Т. И. Мазаева рассматривает земельные ресурсы как основной объект социально-экономических отношений. Управление этим объектом, по мнению автора, должно иметь отличия от управления другими видами ресурсов. Негативная тенденция по снижению качества состояния земли подталкивает исследователей и практиков к разработке новых механизмов управления земельными ресурсами [13].

А. В. Беляков называет агропромышленный комплекс (АПК) Волгоградской области «важным сектором экономики региона», играющим значительную роль в его социально-экономическом развитии. Являясь одним из участников разработанной Стратегии по развитию сельских территорий и эффективному функционированию АПК Волгоградской области ${ }^{3}$, автор утверждает, что ее реализация будет способствовать развитию АПК и потребительского рынка Волгоградской области, поднимет на должный уровень кооперирование между районами и хозяйствами, что в свою очередь послужит устойчивому развитию сельских территорий региона [14].

По мнению Н. И. Оксанич, положительные сдвиги в развитии сельского хозяйства региона следует связывать с основанием агрохолдингов, с помощью которых будет осуществляться «контроль за деятельностью сельхозпроизводителей», а также создаваться «эффективные каналы движения зерновой продукции» [15].

${ }^{3}$ Стратегия по комплексному развитию сельских территорий Волгоградской области и эффективному функционированию агропромышленного комплекса в условиях ВТО с учетом социально-экономических, природно-климатических особенностей [Электронный ресурс]. Режим доступа: http:// pandia.ru/text/78/277/99463.php.

\section{Baikal Research Journal}


К этому мнению присоединяется М. А. Тимошенко, связывая перспективное развитие сельского хозяйства Волгоградской области с созданием «крупного холдингового хозяйствования», способного вывести сельскохозяйственную отрасль региона на новый уровень развития. В свою очередь, эффективная аграрная система региона окажет положительное влияние на уровень жизни сельского населения [16].

О. В. Завгороднева в своих исследованиях при освещении роли кооперации и интеграции в размещении отраслей сельского хозяйства выделяет их как определяющие факторы воздействия на размещение сельскохозяйственного производства. По ее мнению, в одиночку предприятия не смогут выйти из экономического кризиса, а их реструктуризация в процессе объединения создаст благоприятные условия для освоения современных технологий, расширения ассортимента продукции, выхода на другие рынки сбыта, что повлечет за собой новый уровень конкурентоспособности сельскохозяйственного производства [17].

Одним из решений проблем развития АПК Волгоградского региона может стать объединение учебно-научных центров и производственных баз, которое позволит более продуктивно использовать оборудование, трудовые ресурсы, а также финансовые поступления [18].

Таким образом, если обобщить мнения региональных ученых о проблемах развития сельского хозяйства Волгоградского региона, то можно сделать вывод о том, что они должны найти свое отражение при дальнейшей разработке Стратегии по развитию сельских территорий и эффективному функционированию АПК Волгоградской области.

Третье направление представлено авторами, занимающимися оценкой эффективности и результативности работы органов местного самоуправления.

Обзор публикаций по данной проблеме показал, что авторы заняты поиском и формированием новой системы оценки эффективности органов местного самоуправления, так как существующие методики оценки не раскрывают полной картины конечного уровня развития муниципальной территории.

В публикациях данного направления предпринята попытка нахождения взаимосвязи между социально-экономическим развитием муниципальной территории и оценкой эффективной деятельности органов местного самоуправления. Одна группа авторов этого направления исследований, используя коэффициент ранговой корреляции Спирмена, доказала отсутствие связи между этими показателями [19], поэтому авторы настаивают на пересмотре применяемых методик оценки деятельности органов управления и предлагают использовать обобщающий индикатор, отражающий конечный результат деятельности экономических систем муниципалитетов.

Доктор экономических наук, профессор В. Н. Кабанов в своих работах приводит математическую зависимость между показателями, описывающими качество жизни населения и величиной расходов местных бюджетов, анализируя достоинства и недостатки применения этого показателя для оценки эффективности местного самоуправления. Автор рекомендует применять коэффициент эффективности финансового менеджмента конкретного муниципального района при распределении финансовой помощи муниципалитетам [20;21].

Другая группа ученых предлагает модель оценки эффективности и результативности деятельности органов местного самоуправления, которая основывается на трех группах критериев (результативность, эффективность и адаптивность) и показывает зависимость возможности получения синергетического эффекта от стратегических инициатив органов местного самоуправления. С помощью выведенного авторами показателя прироста результативности, эффективности и адаптивности было проведено распределение региональных целевых программ Волгоградской области по данным показателям, которые указали на достаточно низкий уровень

\section{Baikal Research Journal}


результативности и эффективности. Авторы связывают низкие результаты региональных целевых программ с недостаточностью ресурсного обеспечения, а также с нарушением принципа преемственности программных мер [22].

Третья группа исследователей считает, что решение проблемы оценки эффективности работы органов муниципальных образований необходимо начинать с повышения эффективности информатизации, так как это позволит обеспечить оперативность и своевременность предоставления информации о положительных и отрицательных процессах, происходивших на конкретных территориях. Это, в свою очередь, улучшит качество проводимого мониторинга и позволит определить приоритетные направления дальнейшего развития муниципального образования, оптимизирует процесс принятия тех или иных управленческих решений $[23 ; 24]$.

Анализ по данному направлению выявил, что основной проблемой оценки эффективности работы органов местного самоуправления остается разработка и обоснование группы показателей, способных оценить результативность работы этих органов ${ }^{4}$. Подвести итог рассматриваемому направлению помогает высказывание А. В. Шевандрина: «качество муниципального управления проявляется в его воздействии на социально-экономическое развитие муниципальных территорий, не ухудшающим состояние окружающей среды и приводящим к улучшению условий жизни населения» [25].

Таким образом, проведенный обзор показал, что проблемы, связанные с улучшением положения в сельских территориях муниципальных районов, до конца не решены. Однако исследователи Волгоградской области прикладывают максимум усилий для разработки и реализации методов, механизмов, интегральных показателей, способных переломить критическую ситуацию в сельских территориях. В исследуемых работах авторы наметили пути решения этой проблемы: через создание агрохолдингов, объединение учебно-научных центров и производственных баз, оптимизацию системы расселения, нахождение взаимосвязи между социально-экономическим развитием муниципальной территории и оценкой эффективной деятельности органов местного самоуправления.

На наш взгляд, рассмотренные направления требуют дальнейших прикладных исследований и могут быть рекомендованы для разработки не только ученым со степенью, но и аспирантам, магистрантам, студентам. Перечисленные и проанализированные направления можно также использовать и как названия научно-практических конференций для решения обозначенных проблем.

\section{Список использованной литературы}

1. Зайцева О. О. Сельские территории как объект управления: понятие, функции, типологии / О. О. Зайцева // Фундаментальные исследования. - 2013. - № 6, ч. 2. - С. 416-420.

2. Устойчивое развитие сельских территорий Волгоградской области: проблемы и пути решения / С. А. Попова, Т. А. Рудкова, А. С, Горбачева, Е. А. Колпакова // Известия Нижневолжского агроуниверситетского комплекса: наука и высшее профессиональное образование. - 2013. - № 3 (31). - С. 235-239.

3. Попова С. А. Мониторинг качества жизни как один из факторов устойчивого развития сельских территорий / С. А. Попова // Известия Нижневолжского агроуниверситетского комплекса: наука и высшее профессиональное образование. - 2010. - № 4 (20). - С. 200-204.

4. Попова С. А. Особенности государственной поддержки сельскохозяйственных товаропроизводителей Волгоградской области / С. А. Попова, Т. А. Рудкова // Научный вестник Луганского национального аграрного университета. — 2010. — № 4. - С. 213-218.

5. Попова С. А. Проблемы социально-трудовой сферы села Волгоградской области / С. А. Попова, Т. А. Рудкова, Е. А. Карпенко // Региональные проблемы устойчивого разви-

${ }^{4}$ Urban Indicators Guidelines, 2004. Monitoring Habitat Agenda and Millennium Development Goals, United Nations Human Settlements Programme. Mode of access: http://ww2.unhabitat.org/.

\section{Baikal Research Journal}


тия сельской местности : сб. ст. VIII Всерос. науч.-практ. конф. - Пенза : Пензен. гос. с.-х. акад., 2011. - С. 150-153.

6. Плякин А. В. Комплексная оценка социально-экономического развития муниципальных районов в региональной геоинформационной системе / А. В. Плякин. - Волгоград : Волгогр. науч. изд-во, 2011. - 63 с.

7. Плякин А. В. Геостатистический анализ компонентной структуры малых и средних городов Волгоградской области / А. В. Плякин, Е. А. Орехова, К. С. Штеменко // Бизнес. Образование. Право. Вестник Волгоградского Института Бизнеса. — 2013. — № 1 (22). - С. $48-54$.

8. Плякин А. В. Геоинформационное моделирование в оценке конкурентоспособности, устойчивости и безопасности развития муниципальных образований / А. В. Плякин // Бизнес. Образование. Право. Вестник Волгоградского Института Бизнеса. — 2012. — № 3 (20). C. 23-29.

9. Плякин А. В. Пространственный анализ и оценка потенциала экономического развития муниципальных районов / А. В. Плякин, Е. А. Орехова // Бизнес. Образование. Право. Вестник Волгоградского Института Бизнеса. - 2015. - № 1 (30). - С. 98-105.

10. Аляев В. А. транспортная инфраструктура и современная география сел Волгоградской области / В. А. Аляев, М. В. Аляев // Грани познания. — 2014. — № 5 (32). — С. $53-59$.

11. Камаев В. А. Анализ социально-экономического развития муниципальных образований на примере Волгоградской области с использованием моделей DATA MINING / B. A. Kaмаев, М. В. Щербаков, А. С. Аль-Катабери // Известия Волгоградского государственного технического университета. - 2010. - Т. 6, вып. 8. - С. 103-106.

12. Зубова О. Г. Основные направления оптимизации системы расселения сельского населения / О. Г. Зубова, Е. В. Михайлова // Вестник Алтайского государственного аграрного университета. - 2015. - № 7 (129). - С. 153-157.

13. Мазаева Т. И. Анализ использования земель сельскохозяйственного назначения Волгоградской области / Т. И. Мазаева, Д. В. Мазаев // Бизнес. Образование. Право. Вестник Волгоградского Института Бизнеса. - 2011. - № 3 (16). - С. 97-99.

14. Беляков А. В. Экономические аспекты и тенденции развития АПК Волгоградской области / А. В. Беляков, И. В. Лучина // Бизнес. Образование. Право. Вестник Волгоградского Института Бизнеса. - 2014. - № 4 (29). — С. 161-164.

15. Оксанич Н. И. Тенденция Развития Агрохолдингов в Волгоградской области / Н. И. Оксанич // Никоновские чтения. - 2006. — № 11. - С. 217-219.

16. Тимошенко М. А. Эффективность функционирования региональной аграрной системы Волгоградской области / М. А. Тимошенко, Е. Ю. Федосеев, Д. В. Заболотнев // Аграрная наука. - 2012. - № 11. - С. 2-3.

17. Завгороднева О. В. Роль интеграции и кооперации в размещении отраслей сельского хозяйства (на примере Волгоградской области) / О. В. Завгороднева // Известия Оренбургского государственного аграрного университета. - 2011. — № 31 (1). — Т. 3 . - С. 251-254.

18. Цепляев А. Н. Инновационные направления в развитии АПК Волгоградской области на основе интеграции науки и производства / А. Н. Цепляев // Вестник Брянской государственной сельскохозяйственной академии. - 2010. - № 2. - С. 25-31.

19. Калинина В. В. Методологические проблемы и принципы формирования системы оценки эффективности территориального управления с учетом стратегических оринтиров развития / В. В. Калинина, Е. А. Петрова, А. В. Шевандрин // Экономика региона. 2014. - № 4. - С. 261-269.

20. Кабанов В. Н. Оценка эффективности местного самоуправления / В. Н. Кабанов // Бизнес. Образование. Право. Вестник Волгоградского Института Бизнеса. - 2013. № 2 (23). - С. 123-131.

21. Измерения в экономике / под. ред. В. Н. Кабанова. - Волгоград : Экспресс печать, 2012. $-224 \mathrm{c}$.

22. Морозова Н. И. Качество жизни населения как необходимый критерий оценки общенациональной и территориальной системы планирования / Н. И. Морозова // Век качества. - 2011. - № 4. - С. 21-25.

23. Ковалева Н. А. Разработка информационно-аналитической системы мониторинга информатизации муниципальных районов Волгоградской области / Н. А. Ковалева // Вестник Волгоградского государственного университета. Серия 9 , Исследования молодых ученых. 2011. - Вып. 9. - С. 141-143.

\section{Baikal Research Journal}


24. Mitchell A. The ESRI guide to GIS analysis / A. Mitchell. — ESRI Press, 1999. — Vol. 1 : Geographic Patterns \& Relationships. - 186 p.

25. Шевандрин А. В. Оценка социально-экономического развития муниципальных районов Волгоградской области / А. В. Шевандрин // Вестник Волгоградского государственного университета. — 2012. - № 2. - С. 92-100.

\section{References}

1. Zaitseva O. O. Rural territories as an object of management: concept, functions, typologies. Fundamental'nye issledovaniya = Fundamental Research Studies , 2013, no. 6, pr. 2, pp. 416-420. (In Russian).

2. Popova S. A., Rudkova T. A., Gorbatcheva A. S., Kolpakova E. A. Sustainable development of Volgograd Oblast rural areas: problems and solutions. Izvestiya Nizhnevolzhskogo agrouniversitetskogo kompleksa: nauka i vysshee professional'noe obrazovanie = Bulletin of Nizhnevolzhsk agro-university complex: science and higher professional education, 2013, no. 3 (31), pp. 235-239. (In Russian).

3. Popova S. A. Monitoring of standard of life as one of the factors of sustainable development of rural territories. Izvestiya Nizhnevolzhskogo agrouniversitetskogo kompleksa: nauka $i$ vysshee professional'noe obrazovanie = Bulletin of Nizhnevolzhsk agro-university complex: science and higher professional education , 2010, no. 4 (20), pp. 200-204. (In Russian).

4. Popova S. A., Rudkova T. A. Features of governmental support of agricultural commodity producers of Volgograd Oblast. Nauchnyi vestnik Luganskogo natsional'nogo agrarnogo universiteta $=$ Scientific Bulletin of Lugansk National Agrarian University, 2010, no. 4, pp. 213-218. (In Russian).

5. Popova S. A., Rudkova T. A., Karpenko E. A. Problems of socio-labor sphere in villages of Volgograd Oblast. Regional'nye problemy ustoichivogo razvitiya sel'skoi mestnosti. Materialy VIII Vserossiiskoi nauchno-prakticheskoi konferentsii [Regional problems of sustainable development of the countryside. Materials of the 8-th All-Russian Research Conference]. Penza State Agricultural Academy Publ., 2011, pp. 150-153. (In Russian).

6. Plyakin A. V. Kompleksnaya otsenka sotsial'no-ekonomicheskogo razvitiya munitsi pal'nykh raionov $v$ regional'noi geoinformatsionnoi sisteme [Complex analysis of socio-economic development of municipal districts in the regional geo-informational system]. Volgograd Scientific Publishing House Publ., 2011. 63 p.

7. Plyakin A. V., Orekhova E. A., Shtemenko K. S. Geo-statistical analysis of the component structure of small and middle-sized towns of Volgograd Oblast. Biznes. Obrazovanie. Pravo. Vestnik Volgogradskogo instituta biznesa $=$ Business. Education. Law. Bulletin of Volgograd Institute of Business, 2013, no. 1 (22), pp. 48-54. (In Russian).

8. Plyakin A. V. Geo-informational modelling in assessing competitiveness, sustainability and security of developing municipal entities. Biznes. Obrazovanie. Pravo. Vestnik Volgogradskogo instituta biznesa = Business. Education. Lawt. Bulletin of Volgograd Institute of Business, 2012, no. 3 (20), pp. 23-29. (In Russian).

9. Plyakin A. V., Orekhova E. A. Spatial analysis and assessment of economic development potential of municipal districts. Biznes. Obrazovanie. Pravo. Vestnik Volgogradskogo instituta biznesa = Business. Education. Law. Bulletin of Volgograd Institute of Business, 2015, no. 1 (30), pp. 98-105. (In Russian).

10. Alyayev V. A., Alyayev M. V. Transport infrastructure and modern geography of villages in Volgograd Oblast. Grani poznaniya = Borderlines of Knowledge, 2014, no. 5 (32), pp. 53-59. (In Russian).

11. Kamayev V. A., Shcherbakov M. V., Al'-Kataberi A. S. Analysis of Volgograd Oblast municipal formations socio-economic development using DATA MINING. Izvestiya Volgogradskogo gosudarstvennogo tekhnicheskogo universiteta $=$ Bulletin of Volgograd State Technical University, 2010, vol. 6, iss. 8, pp. 103-106. (In Russian).

12. Zubova O. G., Mikhailova E. V. The main optimization directions of the system of rural population settlement. Vestnik Altaiskogo gosudarstvennogo agrarnogo universiteta = Bulletin of Altai State Agricultural University, 2015, no. 7 (129), pp. 153-157. (In Russian).

13. Mazayeva T. I., Mazayev D. V. Analysis of using agricultural lands in Volgograd Oblast. Biznes. Obrazovanie. Pravo. Vestnik Volgogradskogo instituta biznesa = Business. Education. Lawt. Bulletin of Volgograd Institute of Business, 2011, no. 3 (16), pp. 97-99. (In Russian).

\section{Baikal Research Journal}


14. Belyakov A. V., Luchina I. V. Economic aspects and tendencies of development of the agro-industrial complex of Volgograd Oblast. Biznes. Obrazovanie. Pravo. Vestnik Volgogradskogo instituta biznesa = Business. Education. Lawt. Bulletin of Volgograd Institute of Business, 2014, no. 4 (29), pp. 161-164. (In Russian).

15. Oksanich N. I. Development tendencies for agriholdings Volgograd Oblast. Nikonovskie chteniya $=$ The Nikonov Scientific Conference, 2006, no. 11, pp. 217-219. (In Russian).

16. Timoshenko M. A., Fedoseev E. Yu., Zabolotnev D. V. Efficiency of functioning of the regional agrarian system in Volgograd Oblast. Agrarnaya nauka=Agrarian Science, 2012, no. 11, pp. 2-3. (In Russian).

17. Zavgorodneva O. V. The role of integration and cooperation in the location of farming branches (on the pattern of Volgograd Oblast). Izvestiya Orenburgskogo gosudarstvennogo agrarnogo universiteta = Bulletin of Orenburg State Agrarian University, 2011, no. 31 (1), vol. 3, pp. 251-254. (In Russian).

18. Tseplyayev A. N. Innovative directions of Volgograd Oblast agroindustrial complex`s development on the basis of integration between science and production. Vestnik Bryanskoi gosudarstvennoi sel'skokhozyaistvennoi akademii = Bulletin of Bryansk State Agricultural Academy, 2010, no. 2, pp. 25-31. (In Russian).

19. Kalinina V. V., Petrova A. V. Shevandrin E. A. Methodological problems and principles of building a system of assessing efficiency of territorial administration in terms of strategic guidelines of development. Ekonomika regiona = Regional Economy, 2014, no. 4, pp. 261-269. (In Russian).

20. Kabanov V. N. Assessing efficiency of local governments. Biznes. Obrazovanie. Pravo. Vestnik Volgogradskogo instituta biznesa = Business. Education. Law. Bulletin of Volgograd Institute of Business, 2013, no. 2 (23), pp. 123-131. (In Russian).

21. Kabanov V. N. (ed.). Izmereniya v ekonomike [Measurements in economics]. Volgograd, Ekspress pechat' Publ., 2012. 224 p.

22. Morozova N. I. Public standard of life as a necessary criterion of assessing nation-wide and territorial system of planning. Vek kachestva = Century of Quality, 2011, no. 4, pp. 21-25. (In Russian).

23. Kovaleva N. A. Development of informational and analytical system of informatization monitoring in municipal districts of Volgograd Oblast. Vestnik Volgogradskogo gosudarstvennogo universiteta. Seriya 9, Issledovaniya molodykh uchenykh = Science Journal of Volgograd State University. Series 9, Research Studies of Young Scientists , 2011, iss. 9, pp. 141-143. (In Russian).

24. Mitchell A. The ESRI guide to GIS analysis. ESRI Press, 1999. Vol. 1: Geographic Patterns \& Relationships. 186 p.

25. Shevandrin A. V. Assessing socio-economic development of municipal districts in Volgograd Oblast. Vestnik Volgogradskogo gosudarstvennogo universiteta = Science Journal of Volgograd State University, 2012, no. 2, pp. 92-100. (In Russian).

\section{Информация об авторе}

Бергер Юлия Александровна - аспирант, кафедра экономики и управления, Волгоградский институт бизнеса, 400010, г. Волгоград, ул. Качинцев 63, e-mail: berger1981@list.ru.

\section{Author}

Yuliya A. Berger - PhD Student, Chair of Economics and Managemen, Volgograd Institute of Business, 63 Kachintsev St., 400010, Volgograd, Russian Federation; e-mail: berger1981@list.ru.

\section{Библиографическое описание статьи}

Бергер Ю. А. Проблемы и перспективы социально-экономического развития муниципальных районов Волгоградской области (обзор научных публикаций) / Ю. А. Бергер // Baikal Research Journal. - 2016. — T. 7, № 1. — DOI : 10.17150/2411-6262.2016.7(1).15.

\section{Reference to article}

Berger Yu. A. Problems and prospects of socio-economic development of the municipal districts of Volgograd Oblast (review of scientific publications). Baikal Research Journal, 2016, vol. 7, no. 1. DOI: 10.17150/2411-6262.2016.7(1).15. (In Russian).

\section{Baikal Research Journal}

